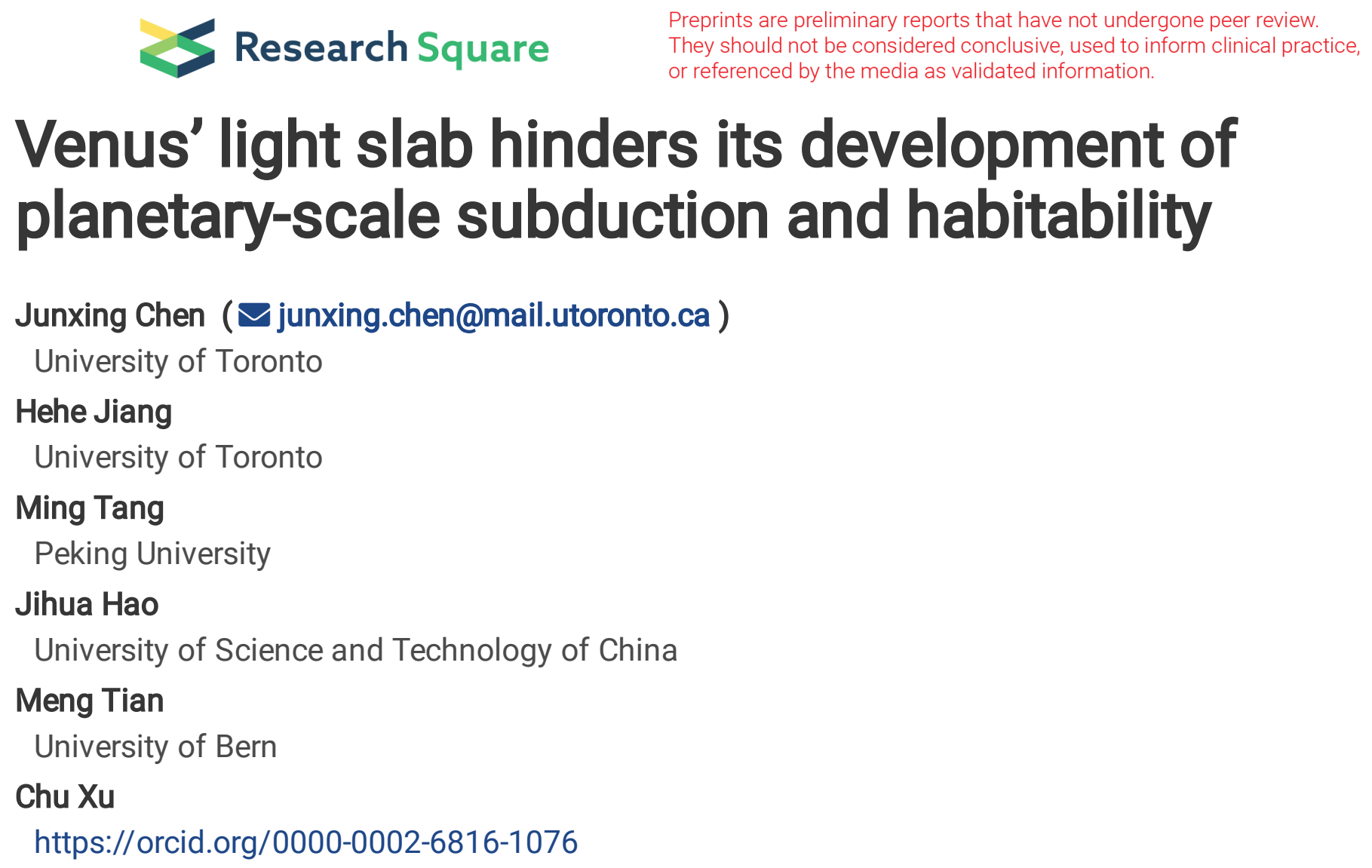

Junxing Chen ( $\nabla$ junxing.chen@mail.utoronto.ca )

University of Toronto

Hehe Jiang

University of Toronto

Ming Tang

Peking University

Jihua Hao

University of Science and Technology of China

Meng Tian

University of Bern

Chu Xu

https://orcid.org/0000-0002-6816-1076

Article

Keywords:

Posted Date: January 7th, 2022

DOI: https://doi.org/10.21203/rs.3.rs-1104964/v1

License: (c) (i) This work is licensed under a Creative Commons Attribution 4.0 International License.

Read Full License 


\section{VENUS' LIGHT SLAB HINDERS ITS DEVELOPMENT OF PLANETARY-SCALE 2 SUBDUCTION AND HABITABILITY}

4 Junxing Chen ${ }^{1 *}$, Hehe Jiang ${ }^{1}$, Ming Tang ${ }^{2}$, Jihua Hao ${ }^{3}$, Meng $\mathrm{Tian}^{4}, \mathrm{Xu}^{\mathrm{Chu}}{ }^{1}$

$6 \quad{ }^{1}$ Department of Earth Science, University of Toronto, Toronto, Ontario M5S 3B1, Canada

$7 \quad{ }^{2}$ Key Laboratory of Orogenic Belt and Crustal Evolution, MOE; School of Earth and Space Science, Peking

8 University, Beijing 100871, China.

$9{ }^{3}$ CAS Key Laboratory of Crust-Mantle Materials and Environments, School of Earth and Space Sciences,

10 University of Science and Technology of China, Hefei 230026, China.

$11{ }^{4}$ University of Bern, Center for Space and Habitability, Gesellschaftsstrasse 6, 3012 Bern, Switzerland 12

13 * junxing.chen@mail.utoronto.ca

14 
16 Terrestrial planets Venus and Earth have similar sizes, masses, and bulk compositions, but only Earth

17 developed planetary-scale plate tectonics. Plate tectonics generates weatherable fresh rocks and transfers

18 surface carbon back to Earth's interior, which provides a long-term climate feedback, serving as a

19 thermostat to keep Earth a habitable planet. Yet Venus shares a few common features with early Earth, such

20 as stagnant-lid tectonics and the possible early development of a liquid ocean. Given all these similarities

21 with early Earth, why would Venus fail to develop global-scale plate tectonics? In this study, we explore

22 solutions to this problem by examining Venus' slab densities under hypothesized subduction-zone

23 conditions. Our petrologic simulations show that eclogite facies may be reached at greater depths on Venus

24 than on Earth, and Venus' slab densities are consistently lower than Earth's. We suggest that the lack of

25 sufficient density contrast between the high-pressure metamorphosed slab and mantle rocks may have

26 impeded self-sustaining subduction. Although plume-induced crustal downwelling exists on Venus, the

27 dipping of Venus' crustal rocks to mantle depth fails to transition into subduction tectonics. As a

28 consequence, the supply of fresh silicate rocks to the surface has been limited. This missing carbon sink

29 eventually diverged the evolution of Venus' surface environment from that of Earth.

\section{Introduction}

32 Venus is regarded as a "twin planet" of Earth, having a slightly smaller radius $(6052 \mathrm{~km})$ and lower gravity

$33\left(\mathrm{~g}=8.87 \mathrm{~m} / \mathrm{s}^{2}\right)^{1}$. Despite these similarities, Venus' $\mathrm{CO}_{2}$-rich $(>90 \%)$ atmosphere $\left(4.8 \times 10^{20} \mathrm{~kg}\right)^{2}$ is $\sim 100$

34 times denser than Earth's $\left(5.15 \times 10^{18} \mathrm{~kg}\right)^{3}$, resulting in a runaway greenhouse effect and extremely high

35 surface temperature of $460^{\circ} \mathrm{C}$. The carbon budget of a planet's surface reservoirs is primarily governed by

36 endogenic degassing and carbon sequestration processes. Magmatism and metamorphism in tectonically

37 active regions release carbon into the atmosphere ${ }^{4,5,6}$, whereas newly formed silicate rocks are subject to

38 weathering that sequestrates atmospheric $\mathrm{CO}_{2}$. The size of this carbon sink depends primarily on the supply

39 rate of fresh silicate reactants or the weathering reaction kinetics ${ }^{7,8}$. Both the input and output fluxes are

40 strongly associated with the tectonic regime of a planet. 
42 The twin planets Venus and Earth show contrasting tectonic characteristics. Planetary-scale subduction

43 does not seem to operate on Venus, and therefore it is widely accepted that Venus is in a stagnant-lid

44 regime ${ }^{9}$. A similar tectonic pattern is inferred to have been prevalent on early Earth, before primitive plate

45 tectonics emerged ${ }^{10,11}$. The origin of plate tectonics on Earth is an ongoing fundamental debate in

46 geosciences ${ }^{12,13}$. Some researchers suggest that plume upwelling and magma loading broke the lithosphere

47 and initiated proto-subduction ${ }^{14,15}$. This lithospheric damage accumulated and formed plate boundaries ${ }^{16}$;

48 self-sustaining subduction further drove plate tectonics on Earth ${ }^{17}$. Plumed-induced subduction sites are

49 also identified around corona structures on Venus ${ }^{18,19}$. The question comes as to why the local subduction

50 failed to trigger plate tectonics on Venus.

52 Here, we explore the mechanisms for the lack of large-scale subduction on Venus from a petrologic

53 perspective and further discuss the consequences. As a crustal slab sinks into the mantle, the increasing

54 pressure produces dense metamorphic assemblages, which, if denser than mantle rocks, would drag the slab

55 further into the mantle and promote plate convergence. Such a process dating back to as early as the

56 Neoarchean on Earth $^{20}$ is favored in cold geothermal conditions ${ }^{16,21}$. In nucleating and sustaining

57 subduction, water plays a vital role as hydration weakens shear zones in the lithosphere ${ }^{22}$, and lubricates

58 the slab interface in the subduction zone ${ }^{23}$. Modern Venus clearly meets neither necessity. However, studies

59 suggest that early Venus might have had a similar liquid ocean and surface temperature to the Archean

60 Earth $^{24}$. Assuming such a favorable environment existed, we explore whether metamorphism on Venus

61 would have resulted in dense slabs. Specifically, we perform forward phase equilibria simulation to model

62 the mineral assemblages, densities of Venus' slabs along typical subduction-zone geotherms. From the

63 modeling results, we discuss how the crustal compositions and densities diverge the tectonic and

64 environmental evolutions of Venus from that of Earth.

65

\section{Modeling slab densities and tectonic development}


67 There are three measured bulk compositions of Venus' crust from the USSR landing probes in the 1980s:

68 Venera $13^{25}$, Venera $14^{25}$ and Vega $2^{26}$. These data were acquired by X-Ray Fluorescence (XRF), and reflect

69 a broadly basaltic crust of Venus. Light elements (e.g., $\mathrm{Mg}$ ) had large uncertainties. In particular, $\mathrm{Na}$

70 concentrations were unavailable from XRF but were estimated using $\mathrm{K}, \mathrm{Mg}$ and $\mathrm{Fe}$ oxides

71 concentration $^{25,26}$. The Venus' crust appears to have higher Al contents and lower contents of divalent

72 cations than that of early Earth ${ }^{27}$. Isostatic compensation models are not able to identify major heterogeneity

73 within Venus' crust by fitting topography and gravity data ${ }^{28}$; without further constraints, we use these three

74 data points to represent the crustal composition of Venus. We model the equilibrium phase relations in the

75 pressure-temperature (P-T) ranges of 0.5-3.5 GPa, 300-900 ${ }^{\circ} \mathrm{C}$ (Fig. 1, S1), using similar approaches

76 reported in ref. 27 (See Methods). The predicted mineral assemblages and mineral compositions enable us

77 to estimate the rock densities. We then test the sensitivity of our modeled slab densities to $\mathrm{Na}, \mathrm{Mg}$

78 concentrations to account for the large uncertainties associated with Venus' crust.

80 The pressure-temperature (P-T) phase diagrams for the three Venus samples are topologically alike- the

81 eclogite-facies assemblages consisting of dense minerals (garnet and omphacite/diopside) are only stable

82 at $>\sim 1.5 \mathrm{GPa}$ (conservatively $\sim 60 \mathrm{~km}$ ) and $>530^{\circ} \mathrm{C}$ (green-shaded in Fig. 1, S1). These Venus' eclogite

83 fields are smaller than those of the Archean-Proterozoic terrestrial samples ${ }^{27}$. The similarities of the

84 moments of inertia and the average densities adjusted to the sizes between Venus and Earth allows us to

85 presume that the mantle density of Venus approaches the Preliminary Reference Earth Model (PREM), and

86 accordingly, these two planets have similar internal and thermal structures ${ }^{29}$. Similar to ref. 27 , we consider

87 two representative geotherms on Venus $-11.3^{\circ} \mathrm{C} / \mathrm{km}$ (warm) and $8.1^{\circ} \mathrm{C} / \mathrm{km}$ (cold). The densities of Venus'

88 slabs are generally lower than Earth's Proterozoic slabs along both geotherms, by up to $0.1-0.2 \mathrm{~g} / \mathrm{cm}^{3}$ (Fig.

$892 \mathrm{a}, \mathrm{b})$. Venus slabs' higher Al contents result in more abundant low-density minerals like chlorite and lower

90 proportions of high-density minerals garnet and pyroxene. The depth that reaches eclogite-facies condition

91 is $5-10 \mathrm{~km}$ greater on Venus than Earth. The Venus' slab densities are about $3.2 \mathrm{~g} / \mathrm{cm}^{3}$ at $55 \mathrm{~km}$ along a

92 warm geotherm (Fig. 2a), or 70 km along a cold geotherm (Fig. 2b). At such depths, the Proterozoic Earth's 
93 slab densities ${ }^{27}$ exceed $3.3 \mathrm{~g} / \mathrm{cm}^{3}$ and approach mantle density $\left(\sim 3.35 \mathrm{~g} / \mathrm{cm}^{3}\right)$. Along both geotherms, the

94 Venus' slab densities shoot up and reach $\sim 3.4 \mathrm{~g} / \mathrm{cm}^{3}$ in the next $10-15 \mathrm{~km}$ due to eclogitization (Fig. 2b,

$95 \mathrm{~S} 3 \mathrm{a}$ ), remaining at 3.35-3.55 $\mathrm{g} / \mathrm{cm}^{3}$ at greater depths (Fig. S3). The slab densities exceed that of the upper

96 mantle at $\sim 65 \mathrm{~km}$ along the warm geotherm (Fig. S3a), and $\sim 75 \mathrm{~km}$ along the cold geotherm (Fig. 2b). The

97 density of metamorphosed Venera 14 approaches that of the Paleoproterozoic high-MgO basalt on Earth ${ }^{27}$.

98 We note that the Venera 14 composition is distinctively Mg-poor, and the effect of compositional variations

99 on the slab density is discussed below.

101 We now explore how the uncertainties in concentrations may influence the equilibrium mineral

102 assemblages and densities. To do this, we first propagate the analytical uncertainties and calculate the

103 density and its likely range by assuming that the three XRF measurements sampled a uniform Venus' crust

104 (Table S2; see Method). As an example, at $525^{\circ} \mathrm{C}$ along the warm geotherm, the distribution of the sampled

105 densities peak at $3.07 \mathrm{~g} / \mathrm{cm}^{3}$, with $1 \sigma$ standard deviation of $\pm 0.03 \mathrm{~g} / \mathrm{cm}^{3}$ (Fig. 2a inset), so the density of

106 Venus' average slab is significantly lower than Earth's. We then run phase equilibrium simulations and

107 slab density calculations at $650{ }^{\circ} \mathrm{C}$ with $\pm 30 \%$ variations in bulk rock Na and $\mathrm{Mg}$ contents (Fig. S5, S6,

108 Fig. 2c, d). The Na content, or the $\mathrm{Na} / \mathrm{Ca}$ ratio, of the crustal protolith, influences the relative stabilities of

109 glaucophane, pyroxene, and garnet ${ }^{30}$ (Fig. S5). However, the density variation due to the uncertainty

110 associated with the $\mathrm{Na}$ content is minor $\left(<0.05 \mathrm{~g} / \mathrm{cm}^{3}\right.$, Fig. $\left.2 \mathrm{c}\right) . \mathrm{Mg}$ and $\mathrm{Fe}^{2+}$ substitute in mafic minerals,

111 such as garnet and pyroxene. Mg-endmembers are less dense, resulting in lower rock density. Mg numbers

$112(\mathrm{Mg} \#=$ molar $\mathrm{Mg} /[\mathrm{Mg}+\mathrm{Fe}])$ of the three samples range from 0.62 to 0.72 . The densities drop significantly

113 as the $\mathrm{Mg}$ contents increase, by up to $0.1 \mathrm{~g} / \mathrm{cm}^{3}$ along the cold geotherm and $0.15 \mathrm{~g} / \mathrm{cm}^{3}$ along warm

114 geotherm, respectively (Fig. 2d). If the bulk Mg\# of Venera 14 were comparable to the others, it would

115 have a similarly low density. Venus has been resurfaced in the past $\sim 500 \mathrm{Myr}^{31,32}$, and therefore its surface

116 rocks represent a relatively modern crust. In the early history of a planet, the melting of a hotter mantle

117 would have produced crustal rocks with higher $\mathrm{Mg}$ contents ${ }^{33}$. The Mg-rich protolith composition results 
118 in less dense metamorphic rocks, especially along a warm geotherm (Fig. 2d). Thereby, our modeling

119 results could be regarded as an upper limit for the slab density on early Venus.

121 On Earth, prototype subduction submerged a slab to the mantle depth, triggered self-sustaining subduction, 122 and initiated plate tectonics ${ }^{10,12,34}$. High-pressure metamorphism creates a dense slab and facilitates slab

123 subduction to greater depths ${ }^{35}$ (Fig. 3b) where the cold core of the subducting slab further contributes

124 negative thermal buoyancy ${ }^{36}$ (Fig. 3c). The negative buoyancy induced by phase transformation might play

125 a particularly important role in the Archean when the basaltic crust was thicker than present ${ }^{37}$. The recycling

126 of slab gives rise to new crustal materials generated at convergent and divergent boundaries (Fig. 3c). On

127 Venus, the modeled slab's densities are consistently lower than Earth's by $>0.1 \mathrm{~g} / \mathrm{cm}^{3}$, and bulk density

128 averaged from shallow depths to $80 \mathrm{~km}$ is $3.18-3.30 \mathrm{~g} / \mathrm{cm}^{3}$ along the warm geotherm, or $3.14-3.25 \mathrm{~g} / \mathrm{cm}^{3}$

129 along the cold geotherm (Fig. S4). The average densities of slabs hardly exceed the mantle density $(\sim 3.35$

$130 \mathrm{~g} / \mathrm{cm}^{3}$ ). At these depths, the mantle lithospheres of the subsiding and overriding plates are of similar

131 temperatures (Fig. 3b), so the negative thermal buoyancy of slab is minor. Given that $80 \mathrm{~km}$ is the

132 overestimation for crustal thickness ${ }^{38}$ and the depth of incipient subduction ${ }^{18}$, spontaneous subduction is

133 unlikely triggered by local and temporal dipping of crust (Fig. 3b). The root of thickened orogen could also

134 delaminate (Fig. 3c), an alternative recycling pathway that might prevail in the Archean. The eclogitized

135 lower crust still needs to be dense enough to introduce gravitational instability ${ }^{39}$, which is unlikely archived

136 on Venus, either. We speculate that light slabs diverged Venus' tectonic regime from Earth in the early

137 stage (Fig. 3d). The difference in tectonic regime eventually leads to contrasting surface carbon budget,

138 environments, and habitability on these two planets.

\section{Earth and Venus' environmental evolution}

141 Both Earth and Venus have considerable amounts of magmatic $\mathrm{CO}_{2}$ degassing (Tmol/yr), despite of their

142 different tectonic regimes. Combining with the metamorphic decarbonation ${ }^{40}$ and clay formation by 143 reversed weathering ${ }^{41}$, the total decarbonation rate is 4 to $29 \mathrm{Tmol} / \mathrm{yr}$ on Earth. As for Venus, the long-term 
144 average volcanic eruption rate is $\sim 0.37 \mathrm{~km}^{3} / \mathrm{yr}^{32}$; given $>4$ wt. $\% \mathrm{CO}_{2}{ }^{42}$ and a density $\sim 2.5 \mathrm{~g} / \mathrm{cm}^{3}$ of the

145 basaltic magma, this endogenic carbon flux on Venus reaches $1 \mathrm{Tmol} / \mathrm{yr}$, half-to-one orders of magnitude

146 smaller than on Earth.

148 Silicate weathering is the primary mechanism of $\mathrm{CO}_{2}$ removal from the atmosphere ${ }^{43,44}$, of which the rate

149 is limited by either the reaction kinetics or the supply rate of reactants ${ }^{7,8}$. The difference in the tectonic

150 regime on Earth (plate tectonics) and Venus (stagnant-lid) lead to a large discrepancy in the tectonic

151 resurfacing rate. On Earth, the large amount of fresh rock produced at active plate boundaries $\left(\sim 30 \mathrm{~km}^{3} / \mathrm{yr}^{\text {, }}\right.$

152 mostly from mid-ocean ridges ${ }^{45}$ and $\operatorname{arcs}^{46}$ ) and a proper land fraction result in a high $\mathrm{CO}_{2}$-consumption

153 rate of 16 to $27 \mathrm{Tmol} / \mathrm{yr}^{47,48}$. The subsequent carbonate deposition $\left(\sim 3.6 \mathrm{Tmol} / \mathrm{yr}^{49}\right)$, followed by subduction

154 or crustal delamination, provides a path for recycling carbonate back to the mantle and establishes a

155 planetary thermostat ${ }^{50}$ (Fig. 3c). When both the surface temperature and weathering rate are primarily

156 controlled by the greenhouse gas content in the atmosphere, negative feedback and thus planetary

157 thermostat could be established ${ }^{50}$. By contrast, subduction on Venus came to a premature end (Fig. 3b, d).

158 Without sufficient new crustal material generated at active plate boundaries, fresh silicate rocks are mainly

159 produced by plume-related volcanism at a rate of $\sim 0.37 \mathrm{~km}^{3} / \mathrm{yr}^{32}$, about $\sim 1 / 100$ the rate of that in Earth $(\sim 30$

$160 \mathrm{~km}^{3} / \mathrm{yr}$ ). Thus, weathering is 'supply limited'51, is less sensitive to temperature, and proceeds at a slow rate

161 on Venus ${ }^{52}$.

163 Efficient resurfacing on Earth, which is brought by active plate tectonics, sustains a long-term negative

164 feedback that prevents Earth's carbon from being accumulated in the atmosphere or being stored entirely

165 in the lithosphere. Even in a supposedly sluggish tectonic regime in the Neoarchean ${ }^{53}$, resurfacing brought

166 by active plate tectonics would still be enough to balance carbon degassing ${ }^{54}$. On the stagnant-lid Venus

167 the $\mathrm{CO}_{2}$ consumption is unlikely to catch up with the endogenic carbon emission, resulting in a long-term

$168 \mathrm{CO}_{2}$ accumulation in Venus' atmosphere, runaway greenhouse climate, and eventual ocean evaporation 
169 within 1 b.y. ${ }^{55}$. In return, the warming surface and lithosphere, together with an anhydrous crust, prevented

170 self-sustaining subduction and locked Venus in a stagnant-lid regime.

171

172 Acknowledgments

173 This work was supported by the NSERC Discovery Grant (RGPIN-2018-03925) to X.C.

\section{Author Contributions}

175 X.C. initiated the idea, J.C. performed simulation, and J.C. and X.C. wrote the first manuscript. All authors

176 contributed to data interpretation and manuscript writing.

\section{Competing Interests}

178 The authors declare no competing interests.

\section{References}

181 1. Fegley, B. Treatise on Geochemistry Ch. 1.19 (Elsevier Science, 2003)

182 2. Basilevsky, A. T., Head, J. W. The surface of Venus. Reports on Progress in Physics 66(10), 1699 183 (2003).

184 3. Trenberth, K. E., Smith, L. The mass of the atmosphere: A constraint on global analyses. Journal of 185 Climate 18(6), 864-875 (2005).

186 4. Marty, B., Tolstikhin, I. N. $\mathrm{CO}_{2}$ fluxes from mid-ocean ridges, arcs and plumes. Chemical 187 Geology 145(3-4), 233-248 (1998).

188 5. Dasgupta, R., Hirschmann, M. M. The deep carbon cycle and melting in Earth's interior. Earth and 189 Planetary Science Letters 298(1-2), 1-13 (2010).

190 6. Le Voyer et al. Carbon Fluxes and Primary Magma $\mathrm{CO}_{2}$ Contents Along the Global Mid-Ocean

191 Ridge System. Geochemistry, Geophysics, Geosystems 20(3), 1387-1424. (2019)

192 7. Kump, L. R., Brantley, S. L., Arthur, M. A. Chemical weathering, atmospheric $\mathrm{CO}_{2}$, and 193 climate. Annual Review of Earth and Planetary Sciences 28(1), 611-667 (2000).

194 8. West, A. J., Galy, A., Bickle, M., Tectonic and climatic controls on silicate weathering. Earth and 195 Planetary Science Letters 235(1-2), 211-228 (2005).

196 9. Smrekar, S. E., Davaille, A., Sotin, C. Venus interior structure and dynamics. Space Science 197 Reviews 214(5), 1-34 (2018). 
10. Lenardic, A. The diversity of tectonic modes and thoughts about transitions between them. Philosophical Transactions of the Royal Society A: Mathematical, Physical and Engineering Sciences 376(2132), 20170416 (2018).

11. Debaille, V. et al. Stagnant-lid tectonics in early Earth revealed by ${ }^{142} \mathrm{Nd}$ variations in late Archean rocks. Earth and Planetary Science Letters 373, 83-92 (2013).

12. Korenaga, J. Initiation and evolution of plate tectonics on Earth: theories and observations. Annual review of earth and planetary sciences 41, 117-151 (2013).

13. Brown, M., Johnson, T., Gardiner, N.J. Plate tectonics and the Archean Earth. Annual Review of Earth and Planetary Sciences 48, 291-320 (2020).

14. Gerya, T. Precambrian geodynamics: concepts and models. Gondwana Research 25(2), 442-463 (2014).

15. Nair, R., Chacko, T. Role of oceanic plateaus in the initiation of subduction and origin of continental crust. Geology 36, 583-586 (2008).

16. Bercovici, D., Ricard, Y. Plate tectonics, damage and inheritance. Nature 508, 513-516 (2014).

17. Gerya, T., Stern, R., Baes, M. et al. Plate tectonics on the Earth triggered by plume-induced subduction initiation. Nature 527, 221-225 (2015).

18. Davaille, A., Smrekar, S., Tomlinson, S. Experimental and observational evidence for plume-induced subduction on Venus. Nature Geosci 10, 349-355 (2017).

19. Piskorz, D., Elkins-Tanton, L. T., Smrekar, S. E. Coronae formation on Venus via extension and lithospheric instability. Journal of Geophysical Research: Planets 119(12), 2568-2582. (2014)

20. Brown, M. Duality of thermal regimes is the distinctive characteristic of plate tectonics since the Neoarchean. Geology 34(11), 961-964 (2006).

21. Landuyt, W., Bercovici, D. Variations in planetary convection via the effect of climate on damage. Earth and Planetary Science Letters 277(1-2), 29-37 (2009).

22. Regenauer-Lieb, K., Yuen, D. A., Branlund, J. The initiation of subduction: criticality by addition of water? Science 294(5542), 578-580 (2001).

23. Schlaphorst, D. et al. Water, oceanic fracture zones and the lubrication of subducting plate boundaries - insights from seismicity. Geophysical Journal International 204(3), 1405-1420(2016).

24. Way, M. J. et al. Was Venus the first habitable world of our solar system? Geophysical research letters 43(16), 8376-8383 (2016)

25. Surkov, Y. A., Barsukov, V. L., Moskalyeva, L. P., Kharyukova, V. P., Kemurdzhian, A. L. New data on the composition, structure, and properties of Venus rock obtained by Venera 13 and Venera 14. Journal of Geophysical Research 89(S02), 393-402 (1984). 
26. Surkov, Y. A., Moskalyova, L. P., Kharyukova, V. P., Dudin, A. D., Smirnov, G. G., Zaitseva, S. Y. Venus rock composition at the Vega 2 Landing Site. Journal of Geophysical Research 91(B13), 215-218 (1986).

27. Palin, R., White, R. Emergence of blueschists on Earth linked to secular changes in oceanic crust composition. Nature Geosci 9, 60-64 (2016).

28. James, P.B., Zuber, M.T. and Phillips, R.J. Crustal thickness and support of topography on Venus. Journal of Geophysical Research: Planets 118(4), 859-875 (2013).

29. Aitta, A. Venus' internal structure, temperature and core composition. Icarus 218(2), 967-974 (2012).

30. Tian, Z. L., Wei, C. J. Coexistence of garnet blueschist and eclogite in South Tianshan, NW China: dependence of $\mathrm{P}-\mathrm{T}$ evolution and bulk-rock composition. Journal of metamorphic Geology 32(7), 743-764 (2014).

31. Turcotte, D. L., Morein, G., Roberts, D., Malamud, B. D. Catastrophic resurfacing and episodic subduction on Venus. Icarus 139(1), 49-54 (1999).

32. Bullock, M. A., Grinspoon, D. H., Head III, J. W. Venus resurfacing rates: Constraints provided by 3D Monte Carlo simulations. Geophysical research letters 20(19), 2147-2150 (1993).

33. Lee, C. T. A., Luffi, P., Plank, T., Dalton, H., Leeman, W. P. Constraints on the depths and temperatures of basaltic magma generation on Earth and other terrestrial planets using new thermobarometers for mafic magmas. Earth and Planetary Science Letters 279(1-2), 20-33(2009).

34. Cawood, P. A., et al. Geological archive of the onset of plate tectonics. Philosophical Transactions of the Royal Society A: Mathematical, Physical and Engineering Sciences 376(2132), 20170405. (2018).

35. Doin, M.P., Henry, P. Subduction initiation and continental crust recycling: the roles of rheology and eclogitization. Tectonophysics 342(1-2), 163-191(2001).

36. Billen, M.I. Modeling the dynamics of subducting slabs. Annu. Rev. Earth Planet. Sci. 36, 325356(2008).

37. Sizova, E., Gerya, T., Brown, M., Perchuk, L.L. Subduction styles in the Precambrian: Insight from numerical experiments. Lithos 116(3-4), 209-229(2010).

38. Gudkova, T. V., Zharkov, V. N. Models of the internal structure of the Earth-like Venus. Solar System Research 54(1), 20-27 (2020).

39. Johnson, T., Brown, M., Kaus, B., Vantongeren, J. A. Delamination and recycling of Archaean crust caused by gravitational instabilities. Nature Geosci 7, 47-52 (2014).

40. Becker, J. A., Bickle, M. J., Galy, A., Holland, T. J. B. Himalayan metamorphic $\mathrm{CO}_{2}$ fluxes: Quantitative constraints from hydrothermal springs. Earth and Planetary Science Letters 265(3-4), 616-629 (2008). 
41. Rahman, S., Aller, R. C., Cochran, J. K. Cosmogenic ${ }^{32} \mathrm{Si}$ as a tracer of biogenic silica burial and diagenesis: Major deltaic sinks in the silica cycle. Geophysical Research Letters 43(13), 7124-7132 (2016).

42. Head, J. W., Wilson, L.Volcanic Processes on Venus. Lunar and planetary science xiii, 312-313 (1982)

43. Isson, T. T., et al. Evolution of the global carbon cycle and climate regulation on earth. Global Biogeochemical Cycles 34(2) (2020).

44. Hilton, R. G., West, A. J. Mountains, erosion and the carbon cycle. Nature Reviews Earth \& Environment 1(6), 284-299 (2020).

45. Bird, P. An updated digital model of plate boundaries. Geochemistry, Geophysics, Geosystems 4(3), (2003).

46. Jicha, B. R., Jagoutz, O. Magma production rates for intraoceanic arcs. Elements 11(2), 105-111 (2015).

47. Coogan, L. A., Gillis, K. M. Temperature dependence of chemical exchange during seafloor weathering: Insights from the Troodos ophiolite. Geochimica et Cosmochimica Acta 243, 24-41 (2018).

48. Wallmann, K., Aloisi, G. The global carbon cycle: geological processes. Fundamentals of Geobiology 20-35 (2012).

49. Sleep, N. H., Zahnle, K. Carbon dioxide cycling and implications for climate on ancient Earth. Journal of Geophysical Research: Planets 106(E1), 1373-1399 (2001).

50. Kasting, J. F. The Goldilocks planet? How silicate weathering maintains Earth "just right". Elements: An International Magazine of Mineralogy, Geochemistry, and Petrology 15(4), 235-240 (2019).

51. Foley, B. J. The role of plate tectonic-climate coupling and exposed land area in the development of habitable climates on rocky planets. The Astrophysical Journal 812(1), 36 (2015).

52. Hakim, K., et al. Lithologic controls on silicate weathering regimes of temperate planets. The Planetary Science Journal 2(2), 49.2 (2021).

53. Korenaga, J. Archean geodynamics and the thermal evolution of Earth. Geophysical MonographAmerican Geophysical Union 164, 7 (2006).

54. Driscoll, P., Bercovici, D. Divergent evolution of Earth and Venus: influence of degassing, tectonics, and magnetic fields. Icarus 226(2), 1447-1464 (2013).

55. Höning, D., Baumeister, P., Grenfell, J. L., Tosi, N., Way, M. J. Early Habitability and Crustal Decarbonation of a Stagnant - Lid Venus. Journal of Geophysical Research: Planets 126(10), (2021). interest. Journal of Metamorphic Geology 16 309-343 (1998). 
57. Carroll, M. R., Rutherford, M. J. Sulfide and sulfate saturation in hydrous silicate melts. Journal of Geophysical Research: Solid Earth 90(S02), C601-C612 (1985).

58. Hacker, B. R., Abers, G. A., Peacock, S. M. Subduction factory 1. Theoretical mineralogy, densities,

\section{Figure Captions}

304 Figure 1. P-T phase diagram in the range $300-650{ }^{\circ} \mathrm{C}, 0.5-2.5 \mathrm{GPa}$ calculated for Vega 2 composition 305 (Table S2). The phase diagram is labeled with mineral assembles and stability boundaries of important 306 phases (garnet, pyroxene, amphiboles). The cold $\left(8.1^{\circ} \mathrm{C} / \mathrm{km}\right)$ and warm $\left(11.3^{\circ} \mathrm{C} / \mathrm{km}\right)$ geotherm are shown 307 as yellow dashed lines. The eclogite-facies assemblages are highlighted in light green. The phase diagrams 308 for the other two compositions are presented in Fig. S1, and the phase relations at higher pressures and 309 temperatures are presented in Figure S2.

311 Figure 2. (a,b) The Earth ${ }^{27}$ (blue) and Venus (red) slab densities along warm and cold geotherms from 300

312 to $650{ }^{\circ} \mathrm{C}$. The inset diagram in Figure 2a shows the statistical distribution of Venus' slab density at $525^{\circ} \mathrm{C}$ 313 along warm geotherm (see Method). The slab densities at higher pressures and temperatures are shown in 314 Fig. S3 and the bulk densities of slabs are shown in Fig. S4. (c,d) The slab densities as functions of the 315 variations of bulk $\mathrm{Mg}$ and $\mathrm{Na}$ concentrations at $650{ }^{\circ} \mathrm{C}$. The phase diagrams are presented in Figures S5 316 and S6.

318 Figure 3. Skematic cartoons illustrating the tectonic evolutions on Earth and Venus, and their diverging 319 carbon cycles. (a) Plume upwelling breaks the lithosphere. (b) Incipient slab dipping on Venus and Earth; 320 eclogitization might trigger self-sustaining subduction. (c, d) Difference in Earth and Venus tectonic and 321 environmental evolution as results of different slab densities and subduction self-sustainabilities (see text 322 for discussions). 
326 Through thermodynamic and mass balance equations, the minerals + fluid equilibria and their compositions

327 are calculable for a fixed rock bulk composition $(\mathrm{X})$ at specific pressure $(\mathrm{P})$-temperature $(\mathrm{T})$ conditions.

328 The equilibrium phase diagrams, also known as "pseudosection", depict the phase relations and outline the

329 areas of stable phase assemblages in P-T, T-X and P-X spaces. In this study, we use the bulk compositions

330 of Venus' crust to plot P-T, P- $\mathrm{X}_{\mathrm{Mg}}, \mathrm{P}-\mathrm{X}_{\mathrm{Na}}$ equilibrium phase diagrams. Assuming that the metamorphism

331 in a hypothesized subduction zone reaches equilibrium, the plotted P-T equilibrium phase diagrams indicate

332 the slabs' mineral assemblages along subduction geotherms. The P- $\mathrm{X}_{\mathrm{Mg}}, \mathrm{P}-\mathrm{X}_{\mathrm{Na}}$ diagrams reflect the

333 influences of $\mathrm{Na}, \mathrm{Mg}$ concentration variances on the mineral assemblages and their compositions. The

334 equilibrium phase diagrams are calculated by using THERMOCALC version 3.33

335 (https://hpxeosandthermocalc.org/), thermodynamic dataset of ds55 (ref. 56) and compatible activity

336 models (Table S3). To estimate the bulk density of a slab averaged from shallow to mantle depths, we

337 model the phase equilibria in a larger pressure and temperature range (up to $3.5 \mathrm{GPa}, 900{ }^{\circ} \mathrm{C}$; Fig. S2). We

338 do not include silicate melts due to a lack of compatible activity models. Incipient melting would lower the

339 bulk density and strength of a slab, impeding slab subduction. The effect of partial melting is further

340 discussed in Supplementary Information.

342 We use the NCKFMASHTO $\left(\mathrm{Na}_{2} \mathrm{O}-\mathrm{CaO}-\mathrm{K}_{2} \mathrm{O}-\mathrm{FeO}-\mathrm{MgO}-\mathrm{Al}_{2} \mathrm{O}_{3}-\mathrm{SiO}_{2}-\mathrm{H}_{2} \mathrm{O}-\mathrm{TiO}_{2}-\mathrm{O}_{2}\right)$ model system.

343 The crust compositions of Venus are represented by three available X-ray fluorescence data $($ Table S1,2)

344 from USSR landing probes Venera $13^{25}$, Venera $14^{25}$ and Vega $2^{26}$. The Venera 13 composition is an 345 alkaline basalt likely consisting of weathered olivine leucitite, nephelinite. Venera 14 and Vega 2 are both 346 weathered N-MORB-like basaltic tholeiite. We assume that ocean existed on the early Venus like the Earth,

347 the basaltic crust could have been hydrated. Progressive dehydration reactions during metamorphism keeps

$348 \mathrm{H}_{2} \mathrm{O}$ saturation. The crustal $\mathrm{Fe}^{3+} /\left(\mathrm{Fe}^{2+}+\mathrm{Fe}^{3+}\right)$ ratios are mainly controlled by the mantle redox condition

349 and partial melting process. Assuming similar settings of the early Earth and Venus, we use the same ratio 
350 as the early Earth $\left(\mathrm{Fe}^{3+} /\left(\mathrm{Fe}^{2+}+\mathrm{Fe}^{3+}\right)=0.1\right.$ in mole, ref. 27). The three Venus data all contain a fair amount

351 of sulfur, which might reflect anhydrite $\left(\mathrm{CaSO}_{4}\right)$ or sulfate-bearing scapolite ${ }^{57}$, the products of chemical

352 weathering by an extreme atmospheric $\mathrm{SO}_{2}$ content. If Venus had liquid ocean at its early stage, the sulfur

353 content would not have been as significant. Thus, we ignore the S contents in our model. We do not remove

354 corresponding $\mathrm{CaO}$ from the bulk composition because sulfur weathering does not introduce additional

$355 \mathrm{CaO}$. The $\mathrm{MnO}$ contents are low, have large uncertainties, and barely affect the phase relations, so we omit

$356 \mathrm{MnO}$ in the model system. The other elements' mass percentage are transferred into mole fraction for the 357 calculation.

359 Phase equilibria modeling predicts quantitative mineral proportions and compositions. The rock densities

$360(\rho)$ are calculated on basis of the information from phase relations and the minerals' thermoelastic 361 parameters, using a similar method as ref. 58:

$$
\rho=\sum_{i=1}^{n} \rho_{i} v_{i}
$$

372 where

$373 v_{i}$ is the volume fraction of a mineral (mode), provided by the phase equilibria modeling results;

$374 \quad \rho_{i}$ is the density of a mineral, calculated using:

$$
\rho_{i}=\frac{\sum_{j=1}^{m} M_{j} x_{j}}{\sum_{j=1}^{m} V_{j} x_{j}}
$$

376 where

$377 \quad M_{i}$ is the molar weight of an endmember, calculated from its formula;

$378 x_{j}$ is the mole fractionation of one end member, provided by the phase equilibria modeling results;

$379 V_{j}$ is the molar volume of an endmember, calculated from the equation of state in ref. 56:

$$
V_{j}=V_{T}\left(1-\frac{4 P}{K_{T}+4 P}\right)^{1 / 4}
$$

381 where 
$V_{T}$ is the molar volume at 1 bar, $T$ (Kelvin in unit), $V_{T}=V_{1,298}\left[1+\alpha_{0}(T-298)-2 \alpha_{0} \alpha_{1}(\sqrt{T}-\right.$

$383 \sqrt{298})]$, in which $\alpha_{0}, \alpha_{1}$ : the thermal expansion parameter;

$384 K_{T}$ : the end-member's bulk modulus at $T$ (Kelvin in unit), $K_{T}=K_{298}\left(1-1.5 \times 10^{-4}(T-298)\right)$, in

385 which $K_{298}$ is the bulk modulus at 298 Kelvin, and $V_{1,298}$ is the molar volume at 1 bar, 298 Kelvin (standard

386 condition).

387

388 In addition to phase relations corresponding to these three individual bulk compositions, we propagate the

389 uncertainties of concentrations, and calculate Venus' slab density and its standard deviation, to explore how

390 likely the slab density of Venus overlap those of Earth. This exercise is time consuming, so we only

391 calculate at $525{ }^{\circ} \mathrm{C}$, along the warm geotherm, where the calculated slab densities of two Venus bulk

392 compositions (Venera 13 and 14) overlap the densities of Earth's Proterozoic slabs (Fig. 2a). The

393 assumption is that these three XRF data all represent one hypothetical uniform crustal composition of

394 Venus. The means and standard variations of Venus' crustal bulk compositions are shown in Tables S1 and

395 S2. At each step, we randomly sample one element's abundance within it range (Gibbs sampler), model the

396 phase relations using the new bulk composition, and calculate the density of the assemblage. We perform

397300 such sampling (Table S4), and then fit the series of calculated densities into a normal distribution for 398 the mean and standard deviation of the density estimate. 


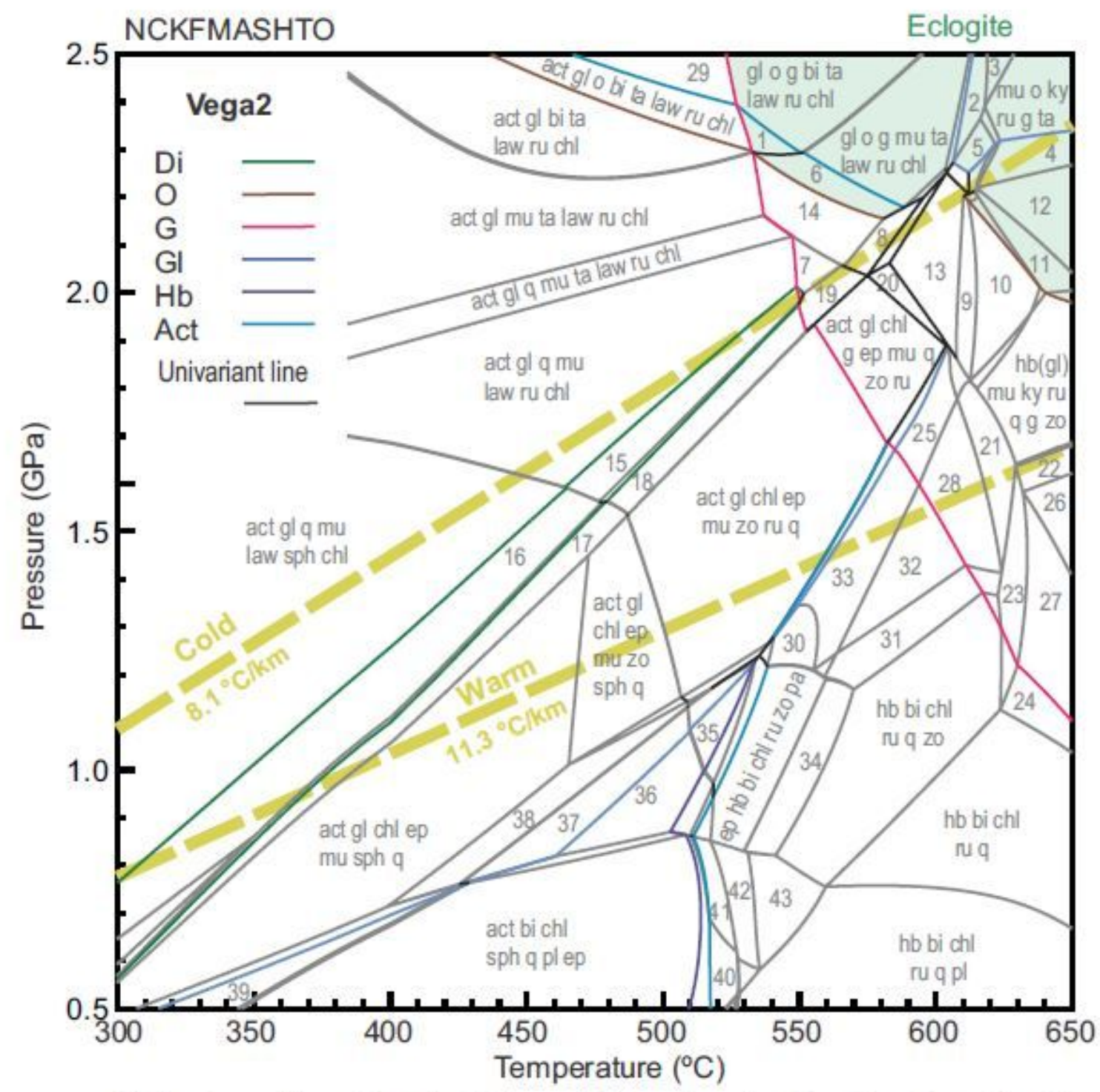

Numbered assemblages: (1)act glo g bi ta law ru chl; (2) mu o kyru chl g ta law; (3) mu o ky rug ta law; (4) gl(hb) mu o ky ru g ta; (5) mu o zo ky ru g ta chl; (6) act gl o g mu ta law ru chl; (7) act gl q mulaw ru chl g; (8) act gl g mu ta ru chleplaw; (9) ep glg mu ky ruzo chl; (10) ep hb(gl) g mu kyru zo; (11) hb(gl) mu o ky ru g zo; (12) hb(gl) o mug ky ru; (13) ep glg mu ta ky ruzo chl; (14) act glg mu talaw ru; (15) act gl q mu law ru chl di; (16) act gl q mu law sph chl di; (17) act gl chl ep mu sph q law; (18) act glchl ep mu ru qlaw; (19) act glchl g ep muruqlaw; (20) $\mathrm{gl}(\mathrm{hb})$ chl gep mu ta ru zo q; (21) hb(g) g muchl ruq zo ky; (22) hb(g) biky ru q g zo; (23) hb bichl ky ruq zo g; (24) hb bi chl kyruq; (25) ep hb g mu chl ru qzo; (26) hb bi kyq ru g; (27) hb bichl kyru qg; (28) hb g mu chl ruq zo; (29) gl o bi talaw ru chl; (30) ep hb chl ruqzo mu pa; (31) hb bichl ru qzo mu; (32) hb mu chl ruq zo; (33) ep hb mu chl ru qzo; (34) hb bi chl ru qzo pa; (35) act ep bi chlru q pa; (36) actchl ep bi sph paq; (37) act gl chl ep bi sph pa q; (38) act gl chl ep mu sph pa q; (39) actmuchl sphqplep; (40) hb bi chl sph qpl ep; (41)ep hb bi chl sphqzo pl; (42) ep hb bichl ru qzo pl; (43) hb bichl ru qzopl

\section{Figure 1}

P-T phase diagram in the range 300-650 $\otimes, 0.5-2.5 \mathrm{GPa}$ calculated for Vega 2 composition (Table S2). The phase diagram is labeled with mineral assembles and stability boundaries of important phases (garnet, pyroxene, amphiboles). The cold $\left(8.1^{\circ} \mathrm{C} / \mathrm{km}\right)$ and warm $\left(11.3^{\circ} \mathrm{C} / \mathrm{km}\right)$ geotherm are shown as yellow 
dashed lines. The eclogite-facies assemblages are highlighted in light green. The phase diagrams for the other two compositions are presented in Fig. S1, and the phase relations at higher pressures and temperatures are presented in Figure S2.
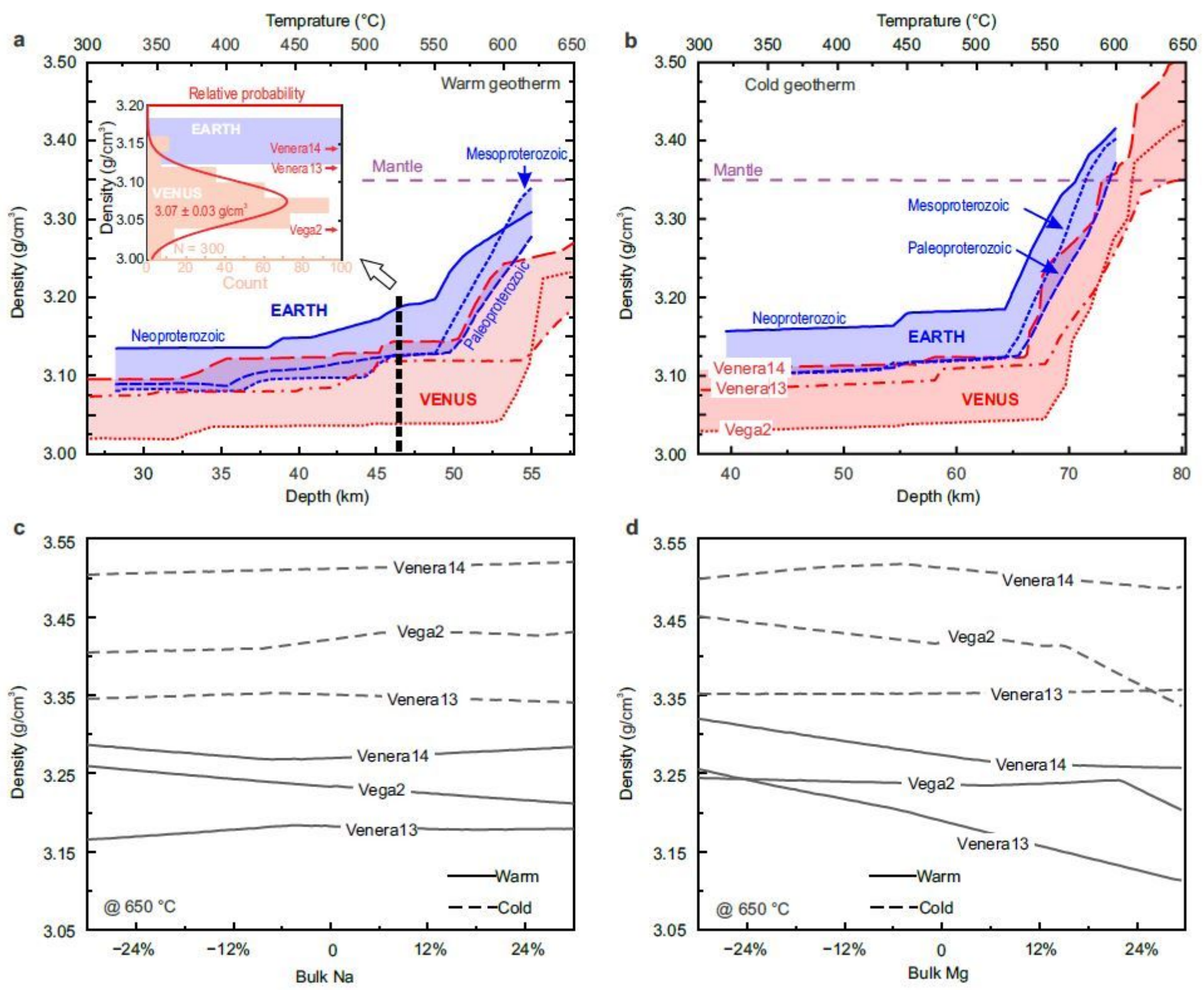

\section{Figure 2}

$(a, b)$ The Earth ${ }^{27}$ (blue) and Venus (red) slab densities along warm and cold geotherms from 300 to 650 \. The inset diagram in Figure 2a shows the statistical distribution of Venus' slab density at 525 along warm geotherm (see Method). The slab densities at higher pressures and temperatures are shown in Fig. S3 and the bulk densities of slabs are shown in Fig. S4. (c,d) The slab densities as functions of the variations of bulk $\mathrm{Mg}$ and $\mathrm{Na}$ concentrations at 650 囚. The phase diagrams are presented in Figures S5 and S6. 


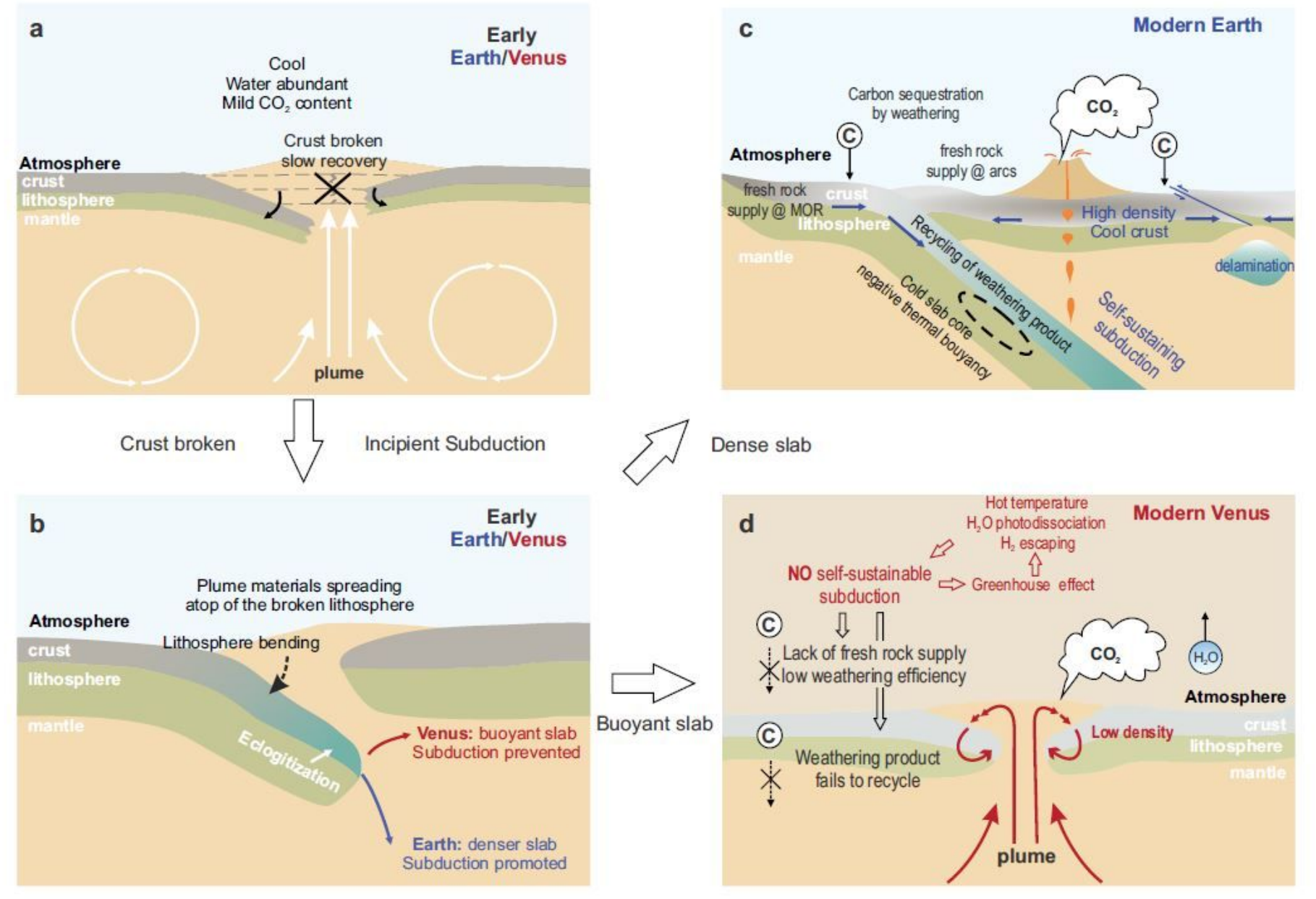

\section{Figure 3}

Skematic cartoons illustrating the tectonic evolutions on Earth and Venus, and their diverging carbon cycles. (a) Plume upwelling breaks the lithosphere. (b) Incipient slab dipping on Venus and Earth; eclogitization might trigger self-sustaining subduction. (c, d) Difference in Earth and Venus tectonic and environmental evolution as results of different slab densities and subduction self-sustainabilities (see text for discussions).

\section{Supplementary Files}

This is a list of supplementary files associated with this preprint. Click to download.

- SupplementaryTable4.xlsx

- Supplementary.docx 